\title{
Introducing a New Member of the Editorial Board of Metallography, Microstructure, and Analysis
}

(C) Springer Science+Business Media New York and ASM International 2016

Editor-in-chief Ryan M. Deacon is pleased to introduce a new member of the Editorial Board of Metallography, Microstructure, and Analysis. The advice and support of the Editorial Board contribute greatly to the ongoing success of MMA.

\section{Daolun Chen}

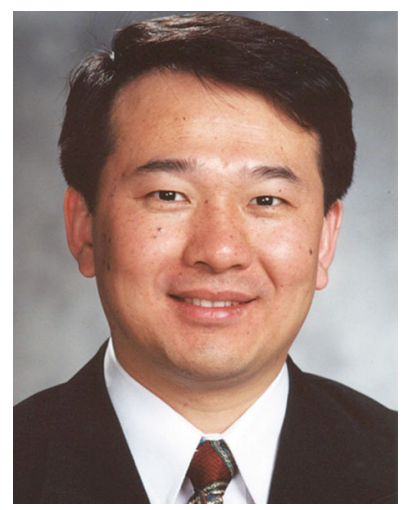

Daolun Chen is a Professor in the Department of Mechanical and Industrial Engineering, Ryerson University, Toronto. He received his B.S. (1983) and M.S. (1986) in Materials Science and Engineering from Northeastern University, China, and a Ph.D. in Materials Science and Engineering from Institute of Metal Research, Chinese Academy of Sciences (1989). He received his second doctorate (Dr.rer.nat.) in Chemistry from the University of Vienna, Austria (1993). In addition, Dr. Chen obtained a
Certificate in Higher Education Teaching at the University of Manitoba in 2000. Prior to joining Ryerson University as an Assistant Professor (2001-2004) and then Associate Professor (2004-2008), Dr. Chen worked as a Post-doc Fellow (1993-1995) and Senior Research Scientist (1995-1997) at the University of Vienna; Research Associate at the University of Manitoba (1997-2000); and Materials and Process Engineer at Bristol Aerospace Ltd., Winnipeg, Manitoba (2000-2001).

His research interests include advanced materials (nanoand bio-materials, composites, etc.) and critical engineering materials (e.g., magnesium alloys, aluminum alloys, titanium alloys), and their mechanical properties, deformation, fatigue, fracture, physical metallurgy, phase transformation, microstructural characterization, materials processing, welding and joining, failure analysis, and life prediction.

Dr. Chen is a recipient of the Premier's Research Excellence Award (PREA), Natural Sciences and Engineering Research Council of Canada DAS Award, MetSoc Award for Research Excellence, Sarwan Sahota Distinguished Scholar Award, Ryerson inaugural Faculty SRC Award, FEAS Research Excellence Award, and Ryerson Research Chair. He has authored or co-authored 324 refereed publications, including 243 journal papers and 81 conference papers, plus an additional 82 non-refereed conference papers/abstracts and 83 research reports. According to a 2011 analysis by the Council of Canadian Academies, Dr. Chen has been identified to be an author of one of the top $1 \%$ most highly cited papers in his field worldwide. 